\title{
Tun Dr. Mahathir's Leadership Communication: The Confucian Perspective
}

\author{
Joyce Lynn-Sze Cheah ${ }^{1, *}$, Norhafezah Yusof $^{1}$ and Mohd Khairie Ahmad ${ }^{1}$ \\ ${ }^{1}$ Communication Department, School of Multimedia Technology and Communication, College of \\ Arts and Sciences, Universiti Utara Malaysia, 06010, Sintok, Kedah.
}

\begin{abstract}
Previous studies have provided valuable insights into the impact of culture on the concept of leadership communication. However, only a few studies that focused on exploring and understanding the values of Confucianism and its impact on the Chinese culture, especially in Malaysia. Thus, this study is among the first study to examine the leadership communication from the perspective of Confucianism towards the leadership of Dr. Mahathir from the perspective of the Chinese community in Malaysia. This study aims to assess the role of Confucian values in Dr. Mahathir's leadership communication. This study interviewed 15 Chinese leaders. The findings reveal that three main Confucian values are relevant to Dr. Mahathir's leadership communication. The Confucian values are Zhi (wisdom), Xin (trust) and Xiao (filial piety). This study provides a new perspective on leadership communication from the context of cultural diversity in Malaysia which emphasizes on Confucian values.
\end{abstract}

\section{Introduction}

Leadership is a set of behaviours that are intended to play a role in achieving the goals of the organization. Studies have shown that culture differences directly affect the effectiveness of leadership and influence the satisfaction and motivation of the followers [9]. Culture signifies the basic values and belief systems of individual that are expected to impact leadership processes.

Among the challenges faced by the leaders in Malaysia are the ways to maintain the development in light of rapid changes in the country. The priority is, therefore, to be able to sustain the impressive achievements made thus far in the rather challenging context of a mullti-racial and multi-religious society, especially the need to understand the cultural thinking of the Chinese community after the General Election (GE13). Therefore, it is important to understand the Chinese culture and values so to manage effectively.

Dr. Mahathir is the fourth Prime Minister of Malaysia, is said to be a charismatic leader [3]. Dr. Mahathir practiced a strong and decisive, both in his leadership and communication style. Malaysia is composed of a majority of Malays, but its business drive comes from the Chinese as the minority group. To keep the economy growing, Dr. Mahathir must allow the Chinese minority to prosper, thus he need to provide some rhetorical favors to the Chinese as well.

\footnotetext{
*Corresponding author: joycecheah@uum.edu.my
} 
Thus, this paper seek to identify the influences of Confucian values in Dr. Mahathir's leadership communication. Through interview with fifteen Chinese leaders, we first explain the concept of leadership communication, then we introduce the core values of traditional Confucian, focusing on content relevant to leadership. We further aim to identify the influence of these values in the leadership communication practices of Dr. Mahathir. Finally, we discuss how these values could be a rich source of understanding for the future leadership research in Malaysia.

\section{Leadership Communication in intercultural context}

Leadership research has begun in the study of sociology and political science. Scholars said that leadership is basically rooted in the language and communication. [4, 5]. The importance of communication to leadership has been stressed by a number of scholars over the years $[2,7]$. Research shows that communication is a powerful catalyst for establishing and sustaining trust. Furthermore, loyalty can be achieved through high level of leader communication.

Leadership practices that are successful in one culture are likely be unsuccessful in another if cultural differences are not considered [6, 8]. Similarly, it can be seen between the Malays and Chinese culture in Malaysia. To understand the ethnic relations between Malays and Chinese, we should identify the different cultural patterns and values that exist among the various ethnic groups in Malaysia.

The Malays believe strongly in religious value. Therefore, they expect their leaders to act as role models who are spiritually and religiously in tune. In communication, the Malays practiced tact and indirectness. The Malays also uphold the value of self-respect, politeness, sensitivity to feelings and value relationships [1].

Meanwhile, the Chinese are motivated by financial rewards [1]. They value hard work, wealth or prosperity, face, harmony and risk taking. It was also observed that the Chinese relationship between leader and follower in work and education was based on the Confucian ideal of filial loyalty.

Despite the cultural difference between the Chinese and Malays, they also possessed the same values on leadership and management principles. The cultural values that were common among the Malays and Chinese were filial piety, honesty, knowledgeable and trustworthiness [13]. Not surprisingly, the Malays shared the value of filial piety with the Chinese where emphasis was put on minding and respecting the parents.

This clearly shows that many challenges and difficulties arising from intercultural communication [9]. This paper suggested that a study on leadership communication from a Chinese perspective should be explored. Therefore, this study was undertaken to explore and understand the values of Confucianism and its impact on Chinese culture in Malaysia.

\subsection{The influences of Confucian values}

In the last two decades, Western theories have been increasingly focusing on the humanistic aspects of successful leadership that considered similar to Chinese values $[6,8,10]$. At the same time, Chinese leadership has adopted many Western leadership attributes. Many scholars recognize that some theories may not be applied by the current intercultural country $[9,14]$. In other words, Malaysian leaders may be unable to effectively manage the country if they are unable to understand the practice of other cultures in Malaysia. Therefore, it is necessary for leaders to understand the culture of the Chinese community by considering the impact of Confucian values, to be effective in the leadership.

To maintain harmony through the relationships, Confucianism promotes five virtues: ren (benevolence), yi (righteousness), li (propriety) zhi (wisdom) and xin (trustworthiness) [12]. In Confucian cultures, leaders are expected to display ren, meaning benevolence or 
humanism. Ren is sometimes translated as "goodwill" or "goodness" towards others. The Confucian leader is expected to be a good-natured leader and to manage with kindness $[11,12]$.

$Y i$, or righteousness means that the leader is expected to uphold the highest standards of moral conduct [11]. Individual self-interest is to be sacrificed for the good of the organization. Meanwhile, Confucius was very concerned with relationships. Appropriate behavior or $l i$, is dictated through Confucian thought in terms of one's relationship with superiors, parents, husband/wife, elders and friends. In a typical Chinese organization, decisions are made by the leaders and followers is expected to carry out the task without question [12]. Employees are expected to be loyal and devoted to their organization and in return, the organization is expected to take care of them.

The value of wisdom or Zhi has always been held in high esteem. Wisdom and age are closely associated in Chinese culture, and it is not surprising to find great deference paid to older members of society [12]. Finally, Confucian leaders are expected to possess xin, or trustworthiness. The Chinese leader is responsible for maintaining control and insuring that all subordinates follow policies consistent with the mission of the organization [12].

Malaysia is a multi-ethnic and multi-cultural society. The Chinese ethnic represent approximately $24 \%$ of the population. Bahasa Malaysia and English are the official languages, but there are many areas where Chinese is spoken. Malaysian Chinese put great emphasis on the education, sticking to the traditions of Chinese culture and teaching themselves Chinese literature. Chinese philosophies, especially Confucianism, greatly impact the Chinese Malaysian and have done so for many years [1]. Clearly, traditional philosophies are still part of the cultural fabric in Malaysia today.

\subsection{Dr. Mahathir Mohamad Premiership}

Under Dr. Mahathir's long Prime Ministership (1981-2003), Malaysia's political culture became increasingly centralized and authoritarian, due to his belief that the multi-ethnic Malaysia could only remain stable through controlled democracy. Dr. Mahathir is a visionary leader and at the same time he is pragmatic, dynamic and intelligent. As a leader, Dr. Mahathir does not only know what has to be done, but also he knows how to get it done [3].

Besides, Dr. Mahathir is one of those few leaders who has the ability to capture our mind when he speaks. His outstanding rhetorical abilities have placed him at the forefront of eloquent leaders in the eyes of his audiences. He speaks calmly, courageously and with magnanimity in words and thoughts [3]. A leading Malaysian politician like Dr. Mahathir with his charismatic character has created the impression that his success is not isolated from his persuasive abilities and has raised the curiosity to investigate his leadership communication particularly in this age which witnesses an interest among researchers to understand the application of traditional values in developing his leadership communication.

In general, charismatic leadership is more appropriate to describe Dr. Mahathir's leadership style in his communication. His speeches that were filled with powerful rhetorical devices had reinforced his credibility as a speaker. His discourse incorporated persuasive and compelling vision to support his main goal, to help unify the people. Apart from being characterized as a charismatic leader, his communication is also helpful in understanding Dr. Mahathir's leadership style. As a leader, power is of the utmost importance to ensure the reform efforts in the administration. It is well-known fact that communication was one of his personal skills as the Prime Minister, especially his skills necessary for interacting with other leaders and societies that would form an important power and his leadership style. 


\section{METHODOLOGY}

This research is based on in-depth interviews with a total of fifteen Chinese leaders in Malaysia. These interviews were done during the period from July 2013 to January 2014.

The interviews were designed to showcase the leadership thoughts and their perception towards Dr. Mahathir's leadership communication. Beyond their leadership status, the leaders also recognized as role models for other leaders for at least two years. In order to collect a holistic perspective on leadership communication, informants were selected to represent three groups of leaders, the political leaders $(n=7)$, leaders of business organizations $(n=5)$ and reporters $(n=3)$. The three group of leaders have been chosen because these groups are believed to give the maximum variation that contributes to the understanding of the concept of leadership communication.

Each leader answered a standard set of semi-structured questions, for a total of eighteen questions. The interviewed were audio-taped (with permission), transcribed, the text prepared, edited and verified by the interviewees before they were analyzed. To analyze the data, the researchers used NVivo 10 software program.

\section{FINDINGS}

The results showed that the Chinese leader highlighted the development of Confucianism as a philosophy of morality and personal ethics in relationships between leaders and followers. Specifically, in this study is their perception towards Dr. Mahathir's leadership communication. From the aspect of leadership, the basic values of Confucianism will produce good leaders, humane and fair. The interviewed leaders mentioned the top three values that leaders should serve as role models to the followers. The three values frequently mentioned are Zhi (wisdom), Xin (trust) and Xiao (filial piety).

\subsection{Zhi 智(wisdom)}

Wisdom or zhi, is defined as knowing, understanding and intelligence. Zhi is one of the main Confucian values to be possessed by a leader. Wisdom also means the ability to think creatively and rationally to solve problem [10]. Such leaders are constantly striving to enhance their knowledge and develop ideas and are always open to new ideas.

Most of the informants (nine informants) agreed that Dr. Mahathir has great wisdom. When talking about Dr. Mahathir, they argued that reading habit has made him a visionary, knowledgeable and capable leader so as to achieve remarkable development and progress in the country.

Informant 15 mentioned that one of the secrets why Tun is a wise leader is because he likes reading. In addition, the knowledge also helps him to make the right decision in different situations.

"A leader who have an extensive knowledge. Tun deserve respect and recognition. Although he was trained as a medical doctor, he was able to express quality ideas in various fields". (Informant 12)

In essence, what is stressed here is the fact that a successful leader must not only continue to learn, but needs to widen his or her visions and horizons. Confucius said a leader must not only have the expertise, talent, ability and diligence, but he also has to care about other people, knowing and willing to help out with [11]. 


\subsection{Xin 信(Trust)}

Trust, or xin addresses the issue of personal integrity with particular emphasis on faithfulness and trustworthiness. For Confucius, trust is very important in interpersonal communication, particularly in leadership communication (Han, 2013). Leaders must be honest and truthful in their words, consistent with their actions, be responsible and must learn from their mistakes. In this way, they will earn the trust of the people. Confucian ideology instructs that leaders need to gain trust of the society in order to mobilize and communicate with them [11].

Four informants have explained that trust links with Dr. Mahathir's leadership communication. Two of the 15 informants said: "As we can see, the past Prime Minister of Malaysia like Tunku Abdul Rahman and Tun Razak, have won the trust of the community. They make a good decision for the country. Similarly, because people believe in his abilities, Dr. Mahathir has proven to the people by transforming Malaysia from an agricultural to a modern state". (Informant 10)

"The Chinese have always been grateful to Tun. Since independence in 1957, the Chinese people have been sharing the wealth and power with the Malays. We can see a lot of Chinese people have succeeded and some have become millionaires during Tun's administration. For example, Robert Kuok, Tan Sri Quek Leng Chan and Tan Sri Vincent Tan. Thus, Malaysians, especially the Chinese community has confidence in Tun". (Informant 2).

\subsection{Xiao 孝(Filial Piety)}

Generally, the concept of Xiao (filial piety) is a key principle in Confucian ideology. The original version of this concept was limited to immediate family, but it evolved to include the relationships outside the family, such as leader-follower [11].

According to Confucian, obedience and respect for parents has developed a way of life that is acceptable [11]. For Informant 3, Xiao is a common practice and is a very important in Malaysia. "The most important thing a child should learn is obedience to his parents. This practice starts from home and extends to the society".

\section{DISCUSSION AND CONCLUSION}

This study found that the Malaysian Chinese emphasizes on Confucian values. The findings demonstrate that leaders with Confucian values are evaluated highly by their followers. It seems that people in the Chinese context would agree with the potential contribution of these values to leadership effectiveness. This study also provides insights into understanding leadership communication and the Chinese culture. Finally, the current study also has practical implications for issues of leadership in Malaysia. The values identified in this study can be applied to other political leaders in a multi-ethnic context to assess leadership behaviors.

As a conclusion, Malaysian leaders need to learn and apply the concepts of moral leadership to improve leadership practices in general. In cross-cultural situations, Malaysian leaders need to understand the importance of Chinese values. Dr. Mahathir's leadership communication behavior accords well against the modern-day Confucian leadership. 


\section{References}

1. A. Asma. Malaysian Management Review 27(1), 3-18 (1992)

2. H. A. Bakar, G. Jian, \& G. Fairhurst. Asian Business \& Management, 13(2), 143-170 (2012)

3. A. Chong, \& K. S. Balakrishnan The Pacific Review. DOI: 10.1080/09512748.2015.1013496. (2015)

4. J. A Conger. Academy of Management Executive, 5(1), 31-45 (1991)

5. K. Czech, \& G. L. Communication Quarterly, 58(4), 431-457 (2010)

6. P. Dorfman, M. Lavidan, P. Hanges, A. Dastmalchian, \& R. House. Journal of World Business, 47, 504-518 (2012)

7. G. T. Fairhurst, \& S. L. Connaughton. Leadership, 10(1), 7-35 (2014)

8. J. S. Gao, J. K. Arnulf, \& H. Kristofferson. Journal of Management, 27, 55-65 (2011)

9. D. I. Jung, \& B. J. Avolio. Academy of Management Journal, 42(2), 208-218 (1999)

10. P. King, \& W. Zhang. Journal of Management Research, 6(2), 1-21 (2014)

11. L. Ma, \& A. S. Tsui. The Leadership Quarterly, 26, 13-24 (2015)

12. G. M. Chen, \& J. Paper presented at the Annual Meeting of the Speech Communication Association (79th, Miami Beach, FL, November 18-21, 1993)

13. D. Zawawi. Int. Journal of Economics and Management, 2(2), 409-426 (2008)

14. J. L. S. Cheah, N. Yusof, \& M. K. Ahmad. Malaysian Journal of Communication, 30 (Special Issue), 129-144 (2014) 